\title{
A LEGITIMIDADE DA NORMA MORAL E JURÍDICA NA ACEPÇÃO DE KELSEN E KANT
}

\author{
THE LEGITIMACY OF MORAL AND LEGAL STANDARDS WITHIN \\ KELSEN AND KANT'S POINT OF VIEW
}

\author{
Neuro José Zambam* \\ Lucio Henrique Spiazzi Algerich Antunes *** \\ Ricardo Antônio Rodrigues ***
}

\begin{abstract}
Resumo: O objetivo deste artigo é apresentar a concepção de Kelsen e Kant sobre a legitimidade da lei moral e da norma jurídica, bem como os seus fundamentos e suas características. Sabendo que o direito e a moral integram a história da humanidade em vista da efetivação das condições de justiça, o seu conteúdo e a sua respectiva prática fomentam a atualização das normas, a fim de responder às demandas do contexto social, normalmente complexo e dinâmico. Com a mesma intensidade as referências inseridas na tradição jurídica representam o fortalecimento do ordenamento social e das instituições. O vigor da democracia depende do amadurecimento dos valores morais, da capacidade de legislar de forma coerente e, assim, contribuir para a estabilidade social seja política, seja institucional. O método investigativo-bibliográfico a partir de autores da tradição orienta este estudo que reflete questões contemporâneas, especificamente, os fundamentos da legitimidade das regras que objetivam a justiça. A moral e a lei de forma complementar são a principal referência para a solução dos graves problemas da atualidade.
\end{abstract}

Palavras-chave: Justiça; Lei; Moral.

\begin{abstract}
The aim of this paper is to present Kelsen and Kant's point of view on both moral law and rule of law legitimacy, its foundations and its features. Knowing that law and moral are an element of the human history aimed for fulfilling the conditions for justice, its contents and their respective practices to promote the updating of standards in order to answer the demands of the social context, which are usually complex and dynamic. In the same way, references in the legal tradition represent the strengthening of the social rules and its institutions. Democracy's strength depends on the maturation of moral values, the capacity for legislating coherently and, thus, for contributing to social stability, either politically or institutionally. Investigative-bibliographic method from traditional authors guides this study, which reflects contemporary issues,
\end{abstract}

\footnotetext{
* Pós-Doutor em Filosofia na Universidade do Vale do Rio dos Sinos - UNISINOS. Doutor em Filosofia pela PUCRS. Professor do Programa de Pós-graduação em Direito da Faculdade Meridional - IMED Mestrado. E-mail: neurojose@ hotmail.com.

** Acadêmico de Ciências Econômicas na Universidade Federal de Santa Maria - UFSM. Acadêmico de Direito no Centro Universitário Franciscano, com intercâmbio em Direito Internacional na Universidade de Lisboa - ULISBOA (2015-2016). E-mail: lucioantunes@outlook.com.

*** Pós-Doutor em Filosofia na Universidade Federal de Pelotas. Doutor em Filosofia pela PUCRS. Professor do Instituto Federal Farroupilha. E-mail: ricardo.rodrigues@iffarroupilha.edu.br.
} 
specifically, the foundations of legitimacy of rules that aim justice. Morality and law, complementarily, are the main reference to solve the tough nowadays problems.

Keywords: Justice; Law; Moral.

\section{INTRODUÇÃO}

O debate sobre a preocupação com as normas jurídicas (escritas) relacionadas aos comportamentos morais se apresenta na Ciência Jurídica rotineiramente, e, embora integrem a tradição, estão em permanente diálogo, conflito e tensão, assim como no cotidiano. A legitimidade da norma jurídica precisa ser respeitada, seja por seu caráter coercitivo ou pelo seu pressuposto de manutenção da ordem cívica. Mas também, pelas regras garantidoras de direitos e obrigações (deveres). Para se responder às questões que emergem dos diferentes ambientes sobre a valoração das leis, reflexões são necessárias a fim de dimensionar se há ou não uma preocupação moral dos atos dos sujeitos no mundo. De modo a concretizar a harmonia de vivência em sociedade, é imperativo visualizar o respeito aos direitos, a legitimidade dos estatutos, e, com isso, o limite do poder estatal. Assim, torna-se possível perceber a lei como a representação da vontade de um soberano, de sacerdotes, ou mesmo da vontade popular, cuja, no percorrer da história, motivou a criação de ordenamentos jurídicos e regras baseadas, ora em posições racionais, ora em espectros transcendentais.

A forma da lei estando positivada se interpenetra com a preocupação da necessária segurança jurídica, do princípio de anterioridade, quanto a entrada em vigor e funcionamento, e das garantias para o devido processo legal, do contraditório e da ampla defesa, perante a relação entre Estado e indivíduo. Contudo, a abordagem tem sentido diferenciado ou divergente acerca da positivação, porque muitas vezes o seu conteúdo está distante dos valores éticos, cujos dão embasamento para a vivência dos sujeitos em sociedade, isto é, da moralidade cotidiana, consistindo então, em uma nebulosa aparência escrita, que está muito mais preocupada com a punição (consequência) do que propriamente com a ação em si.

Desse modo, a existência da norma se revela, sinteticamente, uma preocupação com bens jurídicos, cujos são satisfeitos pelas leis positivadas, criadas em um ambiente democrático. Entretanto, as ações praticadas pelos sujeitos muitas vezes contradizem ao que antes era entendido como certo ou errado para a lei. As transformações ocorrem devido, especificamente, aos estímulos dos avanços 
A legitimidade da norma moral e jurídica na acepção de Kelsen e Kant

econômicos e tecnológicos, culturais e políticos. Dessa forma, uma certa carência no fundamento da lei se dá, pois, essa terá de ser modificada ou sobre passada por outra, o que estabelece um problema sobre as ações praticadas e a construção normativa da lei, fato que alimenta a discussão sobre a valoração ética de ações e sua relação necessária com as leis escritas (positivas).

Com isso, a legitimidade com que a lei é recepcionada traz um dilema presente na reflexão sobre normas, pois na acepção de neutralizar os valores éticos e morais da Ciência Jurídica, Kelsen afasta do ordenamento jurídico os atos e condutas que no mundo dos fatos se colocam juntamente com os posicionamentos morais dos indivíduos. Questão que suscita elucubrações acerca da tarefa de ordenar o convívio social, pois, para Kant, o qual nos fornecerá os matizes categóricos das ações individuais, terá posicionamento diferente, uma vez que realça as condutas como objetos valorativos, percebendo a legitimidade da lei muito além de uma simples condição punitiva.

Assim, na posição de visualizar as diferenças e semelhanças entre os dois respectivos autores, Kelsen e Kant, será indagado sobre qual é o fundamento de legitimidade com que Kelsen vislumbrou na Ciência Jurídica. Satisfaz perceber os pontos em que na leitura de Kant, Hans Kelsen pode ter se abastecido e também quais objetos manteve longe de sua teoria pura, pois foi em Kant que muito dos axiomas da teoria jurídica estiveram a ser percebidos. Embora seja às vezes difícil encontrar os parâmetros de ligação entre os dois em uma rápida análise, muito há de se observar, desde a concepção metafísica acerca da ideia do conhecimento, como também da posição moral com que os sujeitos se relacionam.

Outrossim, ao observar que a moralidade muito mais alimenta a expectativa de ação nos sujeitos partícipes da sociedade, o ponto de discussão está centrado em que deve a lei estar preocupada. Seria com a prática coletiva entendida como Ética e suas devidas decisões particulares definidas por aspectos morais, ou então, a preocupação exclusiva de tentar normatizar toda e qualquer conduta privada que os legisladores/políticos entendem. Ou ainda, estar à procura de bases concretas que oferecem fundamento natural para a definição dos Direitos, dos particulares ou do coletivo, sendo no ambiente democrático em que leis sejam feitas obrigatoriamente respeitando estes alicerces, a partir da leitura dos teóricos naturalistas.

Contudo, são questionamentos válidos em seu berço de reflexão, porém a necessidade de leis positivas e seu entendimento com o indivíduo não devem estar 
Neuro José Zambam

Lucio Henrique Spiazzi Algerich Antunes

Ricardo Antônio Rodrigues

direcionados pela forma com que seu resultado ou sua consequência se dará, mas sim na posição moral com que será percebida a conduta. Assim, nosso objetivo é oferecer uma discussão acerca da legitimidade das normas jurídicas em contraponto as normas morais, segundo concebem Kelsen e Kant, para de modo analítico estudar as teorias, juntamente com as implicações na realidade, para a relevância de identificar as coesões e críticas acerca da efetivação de justiça no caso concreto.

Sendo assim, o método de análise será o investigativo bibliográfico, elegendo aspectos do pensamento de Kant e Kelsen, considerando também para complemento lógico e contribuição acadêmica comentadores acerca dos temas tratados. $\mathrm{Na}$ assertiva de investigar a efetividade da justiça e a ideia de legitimação, serão manuseados meios eletrônicos e outras fontes de pesquisa impressas.

O estudo da teoria de Hans Kelsen formalizou a Ciência Jurídica, estabelecendo limitações científicas e transformando suas considerações sobre categorias valorativas das ações. Pois, a distância definida das normas jurídicas - leis renovou o pensar sobre direitos, fazendo deste objeto o primeiro ponto a se investigar.

Já para um segundo momento, a atenção se volta a Immanuel Kant, a fim de verificar o posicionamento ético das coisas do mundo, tendo atenção moral acerca da normatividade jurídica e sua distância da ideia central que fundamenta a real preocupação da própria lei - o convívio pacífico e cordial entre os sujeitos.

A partir da exposição dos principais argumentos e estudos de ambos os autores, será verificada a compreensão sobre a efetivação de Justiça, importando-se das obras de Kant e Kelsen, para assim, perceber qual o significado de cada uma em sua finalidade. Ainda, por destaque utilizar desta problemática, ou seja, a legitimidade da norma jurídica e da norma moral para perceber qual o impacto e as respectivas consequências entre a "certeza" do justo, ou melhor, a "certeza" em utilizar a lei para justificar a Justiça no caso concreto.

\section{A NORMATIVIDADE EM KELSEN E A LEGITIMIDADE DA CIÊNCIA JURÍDICA}

A norma jurídica é apresentada como proprietária de elementos e pressupostos, cujos em análise se comportam de maneira particular, quando comparada a outras regras e leis das mais diversas Ciências, seja pelo modo que busca interferir nas 
A legitimidade da norma moral e jurídica na acepção de Kelsen e Kant

relações privadas, com regras sobre relações interpessoais, seja pela afirmação do Estado, por lei e por poder. Legislar, executar e julgar são fatores que estão presentes na ideia jurídica, como também ações e omissões, justificadas ou operadas conforme a lei, para se fazer ou deixar de fazer, sendo regras efetivas na vida dos sujeitos.

Desse modo, isso garante como objeto de estudo a norma jurídica, nada mais do que o fato de pertencimento a um "mundo à parte", abstratamente colocado a fim de separar ou afastar tolerâncias, desejos e vontades da realidade. Como as Ciências Naturais possuem propriedades e características próprias, quando de seu estudo sobre objetos e métodos, suas elucubrações que são ora satisfeitas, ora incondicionadas, de se poder resolver, aderem ao modo de exame de seus resultados. Por isso, a Ciência jurídica se faz pertencer a uma ideia de estudo diferenciada, e, embora com perspectivas influentes e influenciáveis, é parte separada do conhecimento. Seus exames não podem ser sempre empíricos nem exclusivamente baseados em eventos sensíveis passados, intuito esse abordado acima, o qual foi responsável e elementar no entendimento de Hans Kelsen, quando da sua trajetória para buscar na Ciência Jurídica uma metodologia própria.

Assim, no conjunto de propriedades das normas jurídicas e na procura dos laços que a ligam e distanciam da realidade, há primeiramente de se compreender o preceito e o pressuposto fático da lei que constroem a regra jurídica enquanto "coisa", à parte do "mundo dos fatos". Nominações essas levantadas por Hans Kelsen em sua Teoria Geral (1998), na busca pela exclusividade de um patamar próximo entre as Ciências Naturais e a Ciência Jurídica, alguns aspectos e intenções foram disciplinados, como dar à lei a legitimidade dos atos, para, então, afastar as normas jurídicas de qualquer outra possibilidade de relativização de uma conduta. Ou ainda, na tentativa de traçar um campo afastado da ética, valores, e demais inclinações filosóficas, o estudo da norma pela norma fora elaborado, trazendo, assim, uma nova forma de visualizar a legitimidade ou não de uma ação - sua positivação enquanto norma jurídica/lei.

Uma vez pela influência do positivismo de Comte $^{1}$, e pela observância de critérios e percepções epistemológicas de $\mathrm{Kant}^{2}$, a Ciência Jurídica de caráter "normativista" fora elaborada. Na perspectiva de estabelecer um "mundo fático", ou seja, aquele constituído pelas ações, condutas e comportamentos humanos, que a característica primeira da norma se fez presente - o pressuposto fático. Esse menciona a realização ou omissão possível para os sujeitos ativos no mundo, de forma a buscar normatizar, ainda que impossível, todas as espécies de atividades que possam ferir bens 
jurídicos. Nesse sentido, a preocupação ainda hoje presente e estabelecida pela doutrina em geral, trata como central à Ciência Jurídica o ramo do conhecimento que se fundamenta pelas relações jurídicas, sejam elas de caráter civil, militar ou penal.

Contudo, fato é que o destaque da norma em sua segunda parte, o preceito, estabelece a consequência jurídica para tal ato ou omissão, cumprimento ou relação, o que demonstra finalmente, a Ciência Jurídica normativista com corporificação de um campo separado, resultando assim no entendimento abstrato de um "mundo jurídico".

Razão essa observa-se no desdobramento de entender um dualismo, ou seja, dois mundos: um de coisas reais e concretas, e outro de abstração/normativo. Fica retomada com ênfase a discussão entre o Direito Natural $^{3}$ e o Direito Positivo, demonstrando a crítica de Kelsen à Ciência Jurídica até então pensada, argumentação exposta em sua Teoria Geral com bastante firmeza e solidez:

O dualismo entre este mundo e o outro, resultante da imperfeição do homem,
desapareceria. O ideal seria o real. Caso se pudesse ter conhecimento da
ordem absolutamente justa, cuja existência é postulada pela doutrina do
Direito natural, o Direito positivo seria supérfluo, ou melhor, desprovido de
sentido. Confrontada com a existência de uma ordenação justa de sociedade,
inteligível em termos de natureza, razão ou vontade divina, a atividade dos
legisladores equivaleria a uma tola tentativa de criar iluminação artificial em
pleno sol (KELSEN, 1998, p.18).

Dessa maneira, a cólera que dará fonte a sua posição acerca da norma jurídica afastada de efeitos valorativos éticos será justificada também por sua posição platônica. Kelsen (1998) entende a ideia metafísica, seja ela moral ou acerca do direito natural, como uma ordem religiosa que aceita qualquer interpretação, redundando em uma falha acerca da efetividade de uma Ciência Jurídica. Coloca a norma como uma necessidade, a fim de blindar os efeitos dos sentidos empíricos, observando que esses são falhos em seu âmago.

Já, Mello (2003) expõe que a formação de um "mundo jurídico" observado doutrinariamente já no fim do século XX, se dá através da incidência da norma jurídica ao fato do mundo real, sendo a norma então, quem define o fato jurídico, possibilitando o nascimento de relações jurídicas com a produção de toda sua eficácia ${ }^{4}$, trazendo direitos e deveres, pretensões e obrigações, e ações ou exceções.

Isso institui (fato jurídico) como artífice de um procedimento exclusivo, dotado de natureza jurídica, quando da ação cuja correspondência interessa a norma. A Ciência Jurídica só é estimulada e adentra em atividade quando da prévia legislação, do 
A legitimidade da norma moral e jurídica na acepção de Kelsen e Kant

período de Vacatio legis, e do pleno respeito aos critérios estabelecidos na sua criação. Só assim um comportamento de um sujeito é retirado do "mundo dos fatos" e direcionado para o "mundo jurídico" (da lei).

Nesse sentido, apresenta um processo de construção para o objetivo de normatizar uma conduta, ou ausência dela. E, nisso, Kelsen percebe na Teoria Geral (1998) a necessidade de uma explicação para realçar o caráter normativo da Ciência Jurídica, que dependia, então, de uma argumentação relativa à norma pura, ou seja, aquela que não beberia jamais se estivesse tangente a receptividade de valores éticos/morais, denominados elementos metajurídicos.

Desse modo, a construção para legitimar a norma jurídica enquanto pura, está sujeita a uma criação a partir de uma norma hipotética fundamental, que daria conta da pressuposição a priori $^{5}$ do entendimento de hierarquia/consolidação de uma estrutura orgânica. Estabelecida pelas normas que dão suporte, que são claramente provenientes da norma hipotética fundamental; e, as demais provindas do exercício de criação da norma por outras normas. Nesse ensejo, Kelsen estipula a distância entre as Ciências Sociais e a Ciência Jurídica, dando corpo e braços para formação de normas e caracterização própria para fins jurídicos.

Observa-se, então, que essa ideia de uma norma hipotética fundamental se constrói de forma a trazer sentido e limitação a todas as demais regras que venham a ser criadas, estando ela em analogia no topo de uma pirâmide, embora não podendo dizer que a Constituição, por exemplo, é a norma hipotética fundamental, pois essa, embora se coloque como principal e hierarquicamente superior nas legislações nacionais, estará a nível didático mais uma vez análogo a uma ideia de norma hipotética fundamental. A Constituição é algo existente positivamente, e na ideia de Kelsen, jamais a norma hipotética estará concretamente existente, sendo ela imutável e metafísica.

Por isso, como Kelsen expõe, seu interesse não está para a justeza ou não da norma, nem para seu conteúdo ou forma, mas sim na ideia de "pureza", ou melhor, na estrutura de pertencimento a um mundo separado entre lei e realidade, não tendo vontade de criar uma super legislação, mas sim uma perspectiva de conhecimento acerca das leis.

Aqui permanece fora de questão qual seja o conteúdo que tem essa Constituição e a ordem jurídica estadual erigida com base nela, se esta ordem é justa ou injusta; e também não importa a questão de saber se esta ordem juridicamente garante uma relativa situação de paz dentro da comunidade por 
Portanto, a argumentação confirma a ausência de valores transcendentes na Ciência Jurídica, embora principalmente quando no estudo das normas muitas vezes é feito o paralelo entre a Constituição e a norma hipotética fundamental, na busca de entender princípios ou fontes de hermenêutica fora das regras escritas (positivas). Atos esses são contemporâneos, providos da evolução desde Kelsen, quanto aos paradigmas da lei escrita, porém não paralelos ao ideal normativo da época.

Outrossim, estabelece-se que a preocupação da Ciência Jurídica para Hans Kelsen está distante do objeto justiça, dos atos ou regras, que darão como finalidade uma busca pela justiça. Kelsen está preocupado com a uniformidade de normas positivas que caracterizem um aspecto técnico, que não seja possível relativização entre os comportamentos e as proibições, por exemplo.

Também é percebido que a configuração da legitimidade no entendimento da Teoria Geral buscar organizar o suporte a aforismos jurídicos pré-estabelecidos ${ }^{6}$, em que o sujeito da lei está para o sistema que a criou, não tendo uma fundamentação em Direitos Naturais ou mesmo em atitudes morais de uma sociedade. O sujeito não se torna centro da lei, mas sim passivo em relação à lei, o que nos remete ao exame da legitimidade no instrumento da norma jurídica em relação à norma moral.

Com isso, Kelsen (1998) criticamente na teoria positivista da Ciência Jurídica, responde à grande diferença entre o estudo do Direito Natural e o Direito Positivo, negando que a análise do segundo provém de uma construção relativista (epistemológica), em que uma vez, tentando negar a validade relativo-hipotética do direito positivo pela invasão do direito natural (metafísico), resultará na quebra do tratamento científico do direito positivo - uma intrusão da metafísica no domínio da ciência.

Entretanto, caro é a história relembrar as crises do passado, e com elas perceber que as "razões", ou melhor, os motivos de anteriormente se pensar de tal forma ou com pressuposição de alguma finalidade, com a ação dos indivíduos e da ética social quando executadas. Assim, no interesse normativo surge a catástrofe do direito positivo na Alemanha Nacional-Socialista, onde o terror "legal" estabeleceu-se". Na atitude e estrito pensamento normativo da época fora possível obedecer à lei, sem qualquer freio 
A legitimidade da norma moral e jurídica na acepção de Kelsen e Kant

quanto a Direitos Naturais, pois, a lei estabelecia a forma com que uma ideia de raça humana pudesse ser boicotada e até mesmo sacrificada.

Ainda, no desenvolvimento normativo da própria União Soviética (USSR), muito embora houvesse uma forma de conduções a estabelecer em decisões jurídicas, pensando-se em aforismas interpretativos, a legislação positiva estabeleceu antes mesmo dos direitos individuais e garantias de vida e liberdade, o projeto de direitos sociais como primeiro àqueles. Nisso, evoca-se mais uma tentativa de normatização total das condutas humanas, ainda que pior, pois estabelece em lei a prerrogativa do Estado como detentor da propriedade e ser/membro coletivo, fazendo da norma jurídica uma regra anterior ao sujeito e seus valores éticos, deveres morais e perspectivas individuais. Dessa forma, Dário M. Vicente (2014) aponta sobre os sistemas jurídicos socialistas: a ausência de uma verdadeira separação de poderes e a restrição das liberdades cívicas e econômicas.

Nesse sentido, a perspectiva proposta por Kelsen sobre a legitimação de normas jurídicas, exclusivamente por pressupostos destas mesmas normas, asseguradas em uma assertiva hipotética, realça a possibilidade de proliferação de barbáries, não somente no "mundo dos fatos", como também no mundo jurídico. Embora haja muitas vezes nos textos legais proibições por parte do Estado para agir, fato é que exemplos históricos se repetiram diversas vezes, fundamentados na lei escrita, ou seja, havia legitimidade jurídica para agir. Assim, é destacável a necessidade da norma moral para observar o que se legitima, ou ainda, perceber a importância de direitos naturais na ação dos sujeitos e na construção normativa.

Também em aspecto epistemológico, a resposta sobre legitimar a norma hipotética fundamental através de uma dogmática, que estabelece um corpo fechado e exclusivo, que não remete à posição valorativa ética na projeção da lei, foge da natureza do sujeito em sociedade. Nessa linha, a acepção de Kelsen resplandece que a norma é satisfeita pelo corpo próprio, e por isso em sua estrutura orgânica traz a legitimação de todo o sistema, desde que observando as próprias regras de criação. Muito embora sua metodologia considere que o processo de relativismo filosófico possibilita a participação individual quando ao conhecimento da norma, essa é uma das poucas diferenças em relação ao absolutismo filosófico. (KELSEN, 2000).

Portanto, não visualizar a aplicabilidade da lei e da construção de normas pelos sujeitos é ter como resultado em algo mecânico, ou seja, no papel é grande a possibilidade de se colocar qualquer fim, meio ou consequência, fazendo disso nuance 
Neuro José Zambam

Lucio Henrique Spiazzi Algerich Antunes

Ricardo Antônio Rodrigues

crítica a perceber em contraponto o ideal de moral e conhecimento em Kant. Verifica-se que os princípios expostos por Kelsen em relação à ideia de norma fundamental se tornam precários quanto ao seu fundamento e praticidade, tema que à frente será novamente discutido.

\section{A MORALIDADE EM KANT E A FORÇA DO IMPERATIVO CATEGóRICO}

As argumentações de Immanuel Kant perante os mais diversos assuntos da filosofia são de grande notoriedade e necessária aprendizagem, fato que justifica autores mais jovens no decorrer da história, como contemporâneos da filosofia, sociologia e da própria Ciência Jurídica, estudarem seus escritos e discutir seus pensamentos.

A moralidade em Kant é apresentada para essa investigação como maneira de perceber a legitimidade moral para as ações e regras sociais, em debate antagônico à legitimidade jurídica de Kelsen, vista anteriormente. Embora haja algumas semelhanças relevantes, a revisão partirá daquilo que Kelsen observou em Kant, cujo vale ressaltar o seguinte trecho acerca da natureza da interpretação, ou da interpretação acerca do objeto da Ciência Jurídica:

\footnotetext{
Assim como Kant pergunta: como é possível uma interpretação, alheia a toda metafísica, dos fatos dados aos nossos sentidos nas leis naturais formuladas pela ciência da natureza, a Teoria Pura do Direito pergunta: como é possível uma interpretação, não reconduzível a autoridades metajurídicas, como Deus ou a natureza, do sentido subjetivo de certos fatos como um sistema de normas jurídicas objetivamente válidas descritíveis em proposições jurídicas? (KELSEN, 1998, p. 225).
}

Desse modo, a matriz com que se coloca as perguntas feitas de muito assemelha à preocupação epistemológica entre ambos os autores, por um lado Kant preocupado com a metafísica do poder de conhecer, e por outro lado a perspectiva de Kelsen, indagando como será possível interpretações que não estejam atreladas a normatividade do ordenamento jurídico - objetividade analítica.

Contudo, a observância crítica que Kelsen utiliza acerca da reflexão em Kant, ora pode ser entendida como fiel à necessidade de se criar elementos para melhorar as relações interpessoais (como leis e regras estritas), ora também pode ser para perceber a diferença de compreensão quanto ao estudo kantiano. 
A legitimidade da norma moral e jurídica na acepção de Kelsen e Kant

Com isso, a ideia de legitimidade moral será preocupação ao pensamento de Kant, buscando os fundamentos do entendimento, das decisões morais e das faculdades para julgamento, para abordar, então, no que consiste o agir de um sujeito. A reflexão sugerida se refere à questão do conhecimento puro, em que em sua primeira crítica discorrerá acerca dos elementos e capacidades de se fazer presentes em nossa cognição.

De modo a construir uma teoria da forma e capacidade para conhecer, estava a perceber no que a ação é movida, transformando os paradigmas da filosofia até o presente e, como novidade para a época, os julgamentos sintéticos a priori foram labutados, a fim de satisfazer a conexão entre a filosofia de base empirista e a de base racionalista.

Verifica-se a condição de observar aquelas “coisas", as quais não necessariamente é preciso conhecer via sentidos, mas a entendemos simplesmente via razão, como o triângulo. São aspectos da nova matriz de estudo acerca do conhecimento que Kant propôs.

Outrossim, desse ponto parte a pesquisa para as elucubrações provenientes das decisões morais, e, para isso, a legitimidade contida em um ato ou em uma tomada de decisão, sendo na ideia da razão primeiramente, os matizes fundamentais de percepção sobre a metafísica, fato pelo qual a resposta de Kant para a discussão acerca da existência de Deus ou não fica concebida na formulação clara de resposta: não se pode conhecer Deus, pois não se possui capacidade para tal ${ }^{8}$.

Além disso, o pensamento de Kant (2013) perpassa os eixos da razão pura e sua perspectiva crítica para colocar o homem como centro do conhecimento. Conforme Motta (2012) alude, o sujeito para a teoria kantiana é o resultado da Revolução Copernicana do Conhecimento, conforme citado por Hume, que coloca o indivíduo a labutar a realidade do mundo. Faz dele o principal ator dos eventos e acontecimentos, fato muito semelhante ao pensamento contemporâneo de Kelsen, em que busca somente nos homens e suas ações/omissões os paradigmas de vivência.

Observa-se, também, que a diferença básica entre a ideia de observar o conhecimento alheio das leis da natureza ou de Deus é percebida como imanente à vontade, ou melhor, coloca-se o homem em papel de artífice perante o conhecer. Por outro lado, na teoria pura da Ciência Jurídica são elementos criados e propositados, não possibilitando a compreensão das atitudes e comportamentos dos sujeitos por eles mesmos, sendo secundários perante uma construção normativa que estreita os laços condizentes entre o agir e a possibilidade de agir. 
Pondera-se o homem não pelas capacidades, mas pelas atitudes concretas, legitimando ou não seus atos somente via resultados auferidos, porém jamais observa-se a moralidade no agir - a consideração dos atos pela capacidade racional ${ }^{9}$.

Dessa maneira, diante da percepção de decisões morais em Kant (1997), estão em observação três principais aspectos: i) Autonomia; ii) Liberdade; e iii) Universalidade. Dessas, a primeira estabelece a condição de não dependência, possibilidade de agir por conta própria, sem necessidade de se curvar ou fazer por alguém. A segunda diz respeito ao agir em si, ou seja, sendo livre o sujeito, pois esse poderá decidir conforme sua razão estiver a comandar, fazendo da liberdade na ação e decisão como ideal para não condicionar uma consequência indesejada. E, por último, a universalidade, ou seja, o pensamento do sujeito ao agir deve ser colocado em reflexão a tomada de decisão para o universo inteiro, tornando seu ato possível a todos, e não prejudicial a todos, agir como se outro pudesse também agir da mesma forma.

Desse modo, os elementos apontados formam o entendimento acerca do imperativo categórico, baseado na pressuposição de agir conforme a própria ação, ou seja, agir por que é bom si mesmo tal conduta. Não estando condicionada à nenhuma prática, ou consequência, nenhuma regra quantitativa ou acerca de prazeres e sofrimentos ${ }^{10}$, está alinhada somente à própria ação (SANDEL, 2014).

O valor dessa ação, como aborda Kant (1997, p. 33), remete ao fato de sua realização possuir como motivo a ação em si, não residindo no efeito que é esperado dela, nem a um princípio que dela seria necessário pedir para satisfazê-la. Então, se poderá encontrar o bem supremo e a realização incondicionada de qualquer questão.

Contudo, o objeto da decisão embora seja ela mesma, e sua incondicionada pressuposição, garante que sua legitimidade não está elevada ao externo, ou seja, não está contida fora do homem. Está legitimada pela moralidade individual, que ordena os caminhos do próprio homem, condizendo com sua relação moral e prática. Torna-se orquestrado o momento do agir em circunspecto ao posicionamento racional.

Portanto, a caracterização de um comportamento perante algum caso concreto será estabelecida via legitimidade moral para Kant, pois a abordagem sugere que o homem, além de autônomo e livre, tomará decisões universais baseadas no bommotivo. Assim, o imperativo categórico ${ }^{11}$ é aquele que reúne as características descritas, importando o modo de agir e a finalidade em si mesma dos comportamentos dos sujeitos. 
A legitimidade da norma moral e jurídica na acepção de Kelsen e Kant

Isso justificará que se observem padrões e perspectivas morais, ou seja, não estará condicionado a uma regra ou lei criada, mas sim ao que se entende moralmente pelas circunstâncias que se colocam na realidade, trazendo desta maneira que a percepção de que alguns direitos são naturais, como por exemplo o valor da vida perante um assassinato.

Nessa ocasião, não haverá ação (matar), pois a forma que se encontra ao sujeito racional está antes mesmo da lei, está em um imperativo, capaz de observar a não conduta sobre determinada questão, percebendo que, embora fosse legal, esse seja um comportamento especificamente imoral, que não há legitimidade para se executar não sendo bom em si mesmo.

\section{A FORÇA DA NORMA POSITIVA E A NORMA MORAL NA EFETIVAÇÃO DA JUSTIÇA}

Na sociedade contemporânea a observância de leis, tratados e regulamentos, tanto em nível nacional quanto internacional, estão presentes no cotidiano, fazendo desses parâmetros comportamentais, conceituais, e até culturais. $\mathrm{O}$ fato torna dinâmico o estudo sobre a legitimidade, pois o entendimento de ser ou não ser proibido, para a maioria da sociedade está diretamente relacionado à condição preexistente em um código de leis e propiciando que o espectro de análise quando nas tomadas de decisões esteja muito mais direcionado e executado conforme a letra da lei.

O que importa geralmente acerca da compreensão desse traço característico das tomadas de decisões diárias é a possibilidade de existir uma interpretação sobre os ordenamentos jurídicos, que traz em si uma hermenêutica ora inerente ao sujeito, ora definida e necessariamente atrelada conforme outra lei. Assim, a problemática revela uma segunda circunstância: a atitude tomada está para ser executada na observância deste próximo momento, ou seja, na interpretação variável perante uma proibição ou omissão de um certo regulamento, o que caracteriza uma vez mais elucubrações positivadas (normativas).

A questão é analisada também por Kelsen na Ciência Jurídica, trazendo a incerteza (interpretação) perante uma "pré-certeza" (a lei). Mas, na intenção de determinar uma teoria geral e pura sobre a Ciência Jurídica que estava a desenvolver-se, percebeu uma vez mais a presença das peculiaridades dos gestos humanos, não sendo estes dados empíricos, idênticos e contínuos. De modo que cada ação é particular, 
embora às vezes similar, difere epistemologicamente das Ciências Naturais, em que todo comportamento por mais executado que seja causará um resultado previamente conhecido. Isso possibilita criar leis universais e torná-las legitimas, já que suas repetidas vezes testadas possuem finais iguais, como por exemplo a gravidade.

Outrossim, a lei escrita possui dois aspectos essenciais que a tornam legítima, ora como força coercitiva, ora como fundamental à sociedade, principalmente porque está contida em um universo de debate, ou seja, no ambiente democrático que satisfaz e torna legítima sua criação, uma vez que respeita parâmetros constituídos propriamente em leis hierarquicamente superiores e também é construída por comissões, delegada a plenários, e aprovada pelos representantes do povo. Muito embora a capacidade discricionária para tornar-se uma regra universal, ou seja, aplicável a toda a sociedade, não importando credo, cor ou condição econômica, seja às vezes relativa. Fica relacionada ao objetivo de trazer harmonia entre os sujeitos, percepção política sobre alguns interesses, ou renovar questões éticas do todo social.

No entanto, a discussão não cessa por essa presença de fatores políticos e sociais, democráticos ou representáveis. A lei quando criada possibilita que esteja atribuído à Ciência Jurídica um fundamento de legitimação, tornando orgânica toda e qualquer tangência a essa norma construída. No que remete à dúvida, a lei quando instituída atribui-se aos mais diversos sujeitos, contudo, preconiza uma submissão aos elementos de uma certa ação executada, eles concordando ou não, fato que por força característica da norma é coercitiva, e está amparado pelo sistema estatal, causando então a obediência dos sujeitos a tal regra, pois como consequência ao descumprimento caberá uma sanção, privação ou punição.

Desse modo, mesmo sendo entendida a necessária percepção de haver coerções a sujeitos que fogem da harmonia e do respeito para com os outros, a regra escrita está para além de qualquer natureza, estando pré-determinada a conceber uma sujeição do indivíduo ao resultado, não interessando sua compreensão sobre o ato a qual poderá exercer. E, como complemento disso, a força positiva entrelaça às relações do sujeito consigo mesmo, causando então, uma pequena ponderação sobre as considerações morais. A questão levará usualmente e por fỉm, a uma caminhada exclusiva às ordens e aos trajetos de "bom viver" estabelecidos juridicamente, enfraquecendo ainda mais o homem como artífice de seu futuro. 
A legitimidade da norma moral e jurídica na acepção de Kelsen e Kant

Além disso, a necessária interlocução do sujeito para com suas atitudes, quando observadas as regras morais, possibilita enaltecer a razão do meio, fim e princípio, sobre determinada conduta, o que uma vez mais torna condizente a sua capacidade de ação em desenvolvimento próprio e com os demais sujeitos, por dar legitimidade a sua ação ou omissão pelos critérios universais, autônomos e livres. E, assim, nos atos do dia a dia busca a efetivação da justiça a partir de seus próprios braços.

Como Bobbio alude acerca da propriedade da ação moral em Kant, segue:

[...] a ação moral é aquela que não é movida por outra inclinação a não ser o respeito à lei (moral). Na conduta moral, cada impulso subjetivo deve ser excluído; o único impulso subjetivo compatível com a moralidade é o sentido de respeito à lei moral, que deve vencer qualquer outra inclinação (BOBBIO, 1995 , p. 54).

Portanto, tendo a subjetividade da limitação ao dever, ou melhor, sendo ela restrita subjetivamente a possibilidade de exercer qualquer ação, se não determinada ao respeito, percebe-se a força legítima para tal ato, não possuindo carência de resultados ou mesmo regras condicionadas. É realizada pelo dever e não simplesmente com o dever.

Ainda, Kant observa o alicerce fundamental, o qual deveria estar como princípio à legislação:

A própria legislação, porém, que determina todo o valor, tem que ter exatamente por isso uma dignidade, quer dizer um valor incondicional incomparável, cuja avaliação, que qualquer ser racional sobre ele faça, só a palavra respeito pode exprimir convenientemente. Autonomia é, pois, o fundamento da dignidade da natureza humana e de toda a natureza racional (KANT, 1997, p. 79).

Dessa forma, a condição de ser legítima ou não determinada regra moral está construída pelos próprios instrumentos que a caracterizam, sendo observados seus motivos, seus fins, e sua razão de ser - o respeito à lei do dever. Contudo, oportuniza a reflexão sobre a efetividade da justiça, sendo possível o questionamento acerca de qual é o ideal de justiça para Kant, observando o paralelo entre normas jurídicas e morais.

Assim, a perspectiva une a correspondência de entendimento de justiça para a projeção de estar relacionada a direitos naturais. Muito embora a discussão aqui não se aprofunde, é necessário perceber a classificação entre direitos inatos e adquiridos e, de modo complementar, perceber que a justiça como Bobbio (1995) apresenta, acerca do 
pensamento kantiano, está relacionada prioritariamente com a liberdade, sendo destaque o potencial das ações conforme esta máxima.

Ou seja, a legitimidade do ato quando moral está estabelecido em si próprio pelo estudo dos três critérios centrais: autonomia; liberdade; e, universalidade. O que se percebe como efetivação de justiça e a relação entre legitimidade jurídica, uma atribuição ao consolidar a lei escrita, ou melhor, das normas positivas para com o juízo $^{12}$, encontrando a liberdade externa e interna. Característica da primeira, estabelecida pelos padrões do Estado, em referência de colocar ordem à sociedade, então, haverá a obrigação em torno do outro, por exemplo, com dever de obedecer uma regra de trânsito. Já, por um segundo momento, a norma moral está contida na liberdade interna. Finalmente, observa a liberdade do próprio ser ao agir, e essa fica legitimada pela ideia de razão e livre arbítrio quando na tomada de decisão particular.

Portanto, Bobbio (1995) observa que a força no caso da coerção da norma jurídica é necessária para haver atos justos, sendo sua tarefa repelir uma outra força que impeça a atuação da justiça, ou seja, uma força injusta. Isso constrói uma harmonia sistemática aos posicionamentos entre a capacidade de legitimação entre as normas morais e jurídicas, buscando finalmente, na efetivação da justiça no caso concreto, uma mescla entre a liberdade interna e externa do comportamento individual.

Ficam enaltecidos os presentes pontos acerca da relação de força tanto de normas jurídicas como morais, implicando na efetividade da justiça pela legitimidade discutida, de modo que o próximo capítulo irá tentar elucubrar qual o poder tanto em discurso como em prática da norma jurídica (leis) perante circunstâncias da vida, naquilo que constituiu a necessidade de argumentação de leis escritas para justificação, autorização e idealização da Justiça.

\section{O PODER DA NORMA EM VISTA DO JUSTO}

Trazer para essa parte final do texto o diálogo, mais lógico do que dialético, do poder da lei em forma de legitimação dos atos praticados, passados e futuros, compromissa uma vez mais a pertinência da investigação em observar a legitimidade das normas jurídicas e morais. Contudo, apresenta-se na sociedade e no próprio conjunto republicano, no caso do Brasil, por exemplo, através de um Estado 
A legitimidade da norma moral e jurídica na acepção de Kelsen e Kant

Democrático, presidencialista e federativo, uma larga conjuntura de regras e ornamentos positivos que fomentam a busca pela Justiça.

Porém, na ideia de abarcar a Justiça em termos gerais, não somente o caso brasileiro, mas sim uma gama vasta de Nações interconectadas por diferentes pontos de vista na rotina política, fica percebido o alcance do Estado em determinar e construir meios para a Justiça no caso concreto, seja a nível micro, ou macro, ainda que pelo menos a tentativa através de mecanismos institucionais de criar regras e metas estatais para a projeção de se "fazer justiça" seja escassa e muitas vezes sem efetividade.

Embora, a abstração do conceito "fazer justiça" seja apenas teórica, formas bastante relevantes, como a própria Democracia, apontam para a solidez de igualdade entre indivíduos perante o voto, por exemplo. Entretanto, a legislação aponta na direção inversa, ou melhor, remete ao sujeito a pré-definição de como agir, seja pelos regulamentos criados no ambiente democrático ou nas relações privadas. Esses são abastecidos não somente a trazer consequências a responsáveis administrativos ou a estipular metas governamentais, mas também na tentativa de criar leis aos atos dos sujeitos, logo interferindo na ponderação individual sobre as próprias condutas.

Observado isto, conclama-se de forma crítica a criação exagerada, confusa e díspar, de diversos e enormes projetos de lei, ou mesmo dos atuais códigos, tornando o poder de se "fazer justiça" como um simples ato de criar leis, o que de certa forma banaliza a perspectiva dos elementos individuais morais já apontados, como a autonomia e liberdade para Kant.

Sendo assim, a retirada de poder da prática individual do dia a dia, pela restrição de agir por leis interventoras na esfera privada do sujeito, realiza uma forma de cooptação mecânica. Ou seja, causa um afastamento intelectual (interpretativo), acerca das mudanças e transformações dos eventos cotidianos, implicando assim que a legitimidade do ato a ser praticado na sociedade está correlata à lei, em que já não se observa uma independência individual para realização de certa atitude. O fato releva a perspectiva de Justiça pelo próprio indivíduo, já que o Estado (criador das leis através dos Poderes Legislativo e Executivo) abandona a máxima de legitimidade - a ação humana.

Ainda, sobre a capacidade de decisão e reflexão das ações individuais, cabe a explicação de Mises (2010) sobre quem move a realidade. Observa que o mecanismo de transformação da sociedade e sua respectiva mola propulsora de movimento é a ação 
do sujeito, denominando que a praxeologia é a ciência que lida com as ações individuais dos homens.

Além disso, na perspectiva kantiana acerca da construção normativa e o interesse primeiro ao fundamento da lei atrelado ao homem e a razão, torna-se tão necessário e máximo para a época em que se vive. Pois, como extraído da obra de Bobbio, fica apresentado que a aplicação da norma positiva não deve ser a única fonte de referência ao agir, mas sim a própria consideração por ela, sua razão de ser:

[O jurista] pode, certamente conhecer e declarar o que venha a ser o direito (quid sit iuris), ou seja, o que as leis, num certo lugar e numa certa época, prescrevem ou prescreveram; mas se é justo o que estas leis prescrevem e o critério universal por meio do qual é possível reconhecer em geral o que é justo ou injusto (iustum et iniustum), permanece-lhe completamente obscuro, se não abandonar por um certo tempo aqueles princípios empíricos, e se (ainda que possa servir-se daquelas leis como excelentes fios condutores), não buscar as origens daqueles juízos na razão pura como único fundamento de qualquer legislação positiva possível (Bobbio, 1995, p. 72-73).

O que repercute o trecho acima para esta pesquisa é a exposição das leis da Ciência Jurídica e o dever para estar relacionada ao fundamento máximo, a razão. E, para isso, a concepção empírica simplesmente não poderá ser artifício criacionista legislativo, sendo necessário considerar o desenvolvimento de independência do sujeito, e com ele a ação movida por si só, não importando ou subjugando a necessária presença de dispositivo legal para atuar e conduzir os comportamentos individuais.

Finalmente, o que causa a pertinência de percepção da Justiça, como algo atrelado ao sujeito, é o próprio enraizamento moral que este está submetido, nas considerações de ser livre e autônomo, capaz de julgar universalmente seus passos e caracterizar que a norma moral consolida seu posicionamento enquanto ser humano. Para complemento disso, não se necessita invocar a norma jurídica para atuar, viver e pensar. Não se trata de estar legislado o comportamento justo (certo ou errado, equilibrado ou não), mas a independência em afirmar seu próprio sujeito para os enfrentamentos diários, impulsionando a reflexão para buscar a Justiça.

Portanto, o tratamento da legitimidade moral realça as competências em acordar que a independência de agir é satisfeita não pela consequência (normas jurídicas legisladas), mas sim pela causa de encontrar o meio de agir perante os momentos do cotidiano. É válido então, chegar a essa discussão de certo e errado pelos pressupostos da razão, e não simplesmente pela observância técnica/mecânica de normas préformuladas. 


\section{CONSIDERAÇÕES FINAIS}

A construção de convencimentos filosóficos presentes nesta investigação adere ao tema central, em que tentar fundamentar a legitimidade das normas jurídicas e morais realça a pesquisa para além de uma simples abstração, sendo da necessária revisão os conceitos e atributos vistos durante o texto acerca das complementações entre as normas jurídicas e morais. Ambas realizam um processo conjunto aos indivíduos, muitas vezes responsáveis pela capacidade de tomada de decisão no seio de grupos, por exemplo, mas de modo a contribuir ainda mais, percebe-se que a convicção de existir leis e da mesma maneira normas morais para a atividade dos sujeitos na sociedade irá depender da eficácia em mesclar ambas na tentativa de possibilitar atitudes justas.

Assim, ficam interconectados os pensamentos e reflexões dos autores principais do texto, Kelsen e Kant, no intuito de uma vez mais discutir os impactos que as leis e as ações realizam na efetivação da Justiça, sendo capaz de influenciar no comportamento e relação social dos indivíduos.

Dessa forma, os capítulos abordaram algumas particularidades específicas, ao empesar pela normatividade kelsiana e com ela a legitimidade da Ciência Jurídica, seu modo de apresentação e as normas caracterizadoras de seu estudo. Na sequência, a obra de Kant fez parte na busca das normas morais, a moralidade kantiana, e as considerações, ou melhor, regras para tal.

Destarte, nesses dois primeiros enxertos foram discutidos teoricamente os aspectos que retratam a idealização de cada ramo, sendo da norma jurídica um dado real presente e concreto nos Estados nacionais, e por outro lado, a ação/moralidade individual pertencente aos seres humanos, o que reafirma a necessidade de haver discriminação individual para agir perante estreitas e específicas condições, de modo que a legitimidade da ação parta da razão. Através de um imperativo que dê fundamento a conduta, e aliado a isso, deve a lei escrita ser um instrumento de consolidação e orientação sugestiva para o sujeito.

Outrossim, a força da norma jurídica/positiva para efetivação da Justiça fora colocada no seio do debate, e para tal realizado o contraste entre as normas morais, implicando assim na necessidade de expor especificamente acerca do arcabouço de dependência do sujeito na atualidade para perceber a lei como máxima às suas ações, como sendo a norma jurídica o argumento legítimo para agir e se comportar. Com isso, 
se constrói o foco e devido escopo entre a legitimidade da ação pelo dever e para com o dever, como a obra de Kant sinaliza.

Respectivamente, a norma jurídica enaltece o bom-viver como fruto do adestramento e a observância de parâmetros já definidos, entretanto, quando vista a conduta por sua atitude própria, movida pelo motivo bom em si mesmo, cabe ao sujeito a utilização da razão e caracterização da legitimidade.

Portanto, a presença da lei escrita, muito embora possua em si elementos necessários ao bom viver, por questões principalmente ligadas à premissa de "segurança jurídica”, essa se coloca como contrária a reflexão e possível legitimidade para agir do sujeito, já que não fundamenta a ação, mas sim traz regramento ao agir. Então, o discernimento ou saída da ignorância como apontava Kant depende da vontade em realizar por si mesmo, de criar a expectativa e condicioná-la ao agir e de mover o interesse e o motivo para se chegar à reflexão do agir, e como proceder, de modo que o sujeito esteja legitimamente se comportando segundo ele mesmo, com liberdade e perspectiva moral para sua ação quando de confronto a outrem.

Assim, o que traz à tona investigar a legitimidade das normas jurídicas está relacionado ao momento contemporâneo que vivemos, o qual sinaliza a derrocada de valores para com a política nacional das democracias modernas, fazendo diretamente disso efeito na legislação jurídica. Torna-se imputável visualizar que a perda de legitimidade de algumas regras está fatalmente interligada com a falta de noção entre a moral e a realidade, por parte dos legisladores e dos cidadãos. De modo análogo, a característica presente no consenso social de compreender a lei como legítima a agir subjuga o próprio sujeito, ferindo os princípios da natureza humana que em uma única palavra se fazem entender como liberdade.

Além disso, o potencial que se estabelece através das normas morais e a condução das ações embasadas em pressupostos bons em si mesmo é caro a projeção em realizar ponderações sobre, e para a Justiça, uma vez que a arguição de Kelsen e Kant acerca da objetividade e motivo, respectivamente, são linhas tênues para a construção conjunta da afirmação da legitimidade dos comportamentos. Talvez também a necessidade de limite, ou seja, do uso e fruto de cada linha de pensamento como barreira a absoluta certeza de uma em espectro de outra, sendo assim de principal referência a efetividade da Justiça fundamentada na independência, característica que consolida a busca pela capacidade racional de tomar decisões no cotidiano e que 
A legitimidade da norma moral e jurídica na acepção de Kelsen e Kant

estimula cada vez mais o sujeito como centro do mundo e de seu próprio pensamento, como uma possibilidade de evolução da sociedade, local e Universal.

\section{REFERÊNCIAS}

BOBBIO, Norberto. Direito e Estado no Pensamento de Emanuel Kant. 3. Ed.

Tradução de Alfredo Fait. Brasília: Editora Universidade de Brasília, 1995.

FERRY, Luc. Kant: uma Leitura das Três Críticas. 2. Ed. Tradução de Karina Jannini, Rio de Janeiro: Difel, 2010.

GOLDENSOHN, Leon. As Entrevistas de Nuremberg: conversas de um psiquiatra com os réus e as testemunhas. Tradução de Ivo Korytowski. São Paulo: Companhia das Letras, 2004.

KANT, Immanuel. Crítica da Faculdade do Juízo. 2. ed. Tradução de Valério Rohden e Antonio Marques. Rio de Janeiro: Forense Universitária, 1995.

Crítica da Razão Pura. Tradução de Alexandre Fradique Morujao. 8. ed.

Lisboa: Calouste Gulbenkian, 2013.

Fundamentação da Metafísica dos Costumes. Tradução de Paulo Quintela. Lisboa: Edições 70, 1997.

KELSEN, Hans. A Democracia. 2. ed. São Paulo: Martins Fontes, 2000.

Teoria Pura do Direito. 6. ed. Tradução: João Baptista Machado. São Paulo: Martins Fontes.1998.

MELLO, Marcos Bernardes de. Teoria do fato Jurídico: plano da Existência. 12. ed. São Paulo: Saraiva. 2003.

MISES, Ludwig Von. Ação Humana. São Paulo: Instituto Ludwig von Mises Brasil, 2010.

MORENTE, Manuel García. Fundamentos de Filosofia. 8. ed. Tradução de Guilhermo de la Cruz Coronado. São Paulo: Mestre Jou, 1980.

MOTTA, Carlos. Kant e o Sono Dogmático: Influência de Hume na compreensão da causalidade. Revista Páginas de Filosofia. v. 4, n.1, p. 17-38, jan/jun, 2012.

SANDEL, Michael J. Justiça: O que é fazer a coisa certa. 16. ed. Tradução de Heloísa Matias e Maria Alice Máximo. Rio de Janeiro: Civilização Brasileira, 2014.

VICENTE, Dário Moura. Direito Comparado. 3. ed. Vol. 1. Coimbra: Almedina, 2014. 


\footnotetext{
${ }^{1}$ Auguste Comte elabora em meados da década de 30 do século XIX a teorização acerca da necessária positivação das Ciências Sociais. Tempo o qual entre a filosofia, sociologia e política, Comte sugeria a formulação positiva de regras para o método de estudo destas ciências e suas problemáticas. Sugerindo desde dados estatísticos exclusivos para a sociologia, como também análises de leis universais para problemas metafísicos.
}

${ }^{2}$ Immanuel Kant cerca de dois séculos antes de Hans Kelsen construiu uma das mais notáveis contribuições a filosofia do conhecimento. Sua ideia acerca dos juízos sintéticos a priori, levantou grande influência a Kelsen, que utilizando de forma clara quando da ideia de lei, pois para ser legal há de haver a norma, esta com conhecimento a priori dos sujeitos. Entretanto, a leitura de Kant por Kelsen não necessariamente seguiu a ideia ética sobre decisões morais, trazendo uma certa disparidade do pensamento de ambos. Análises que serão a frente abordadas. ${ }^{3}$ A construção acadêmica parte da ideia de Direito Canônico, primeiramente, de surgimento na Idade Média, para após as considerações modernas e com elas a influência do iluminismo, observar que o Direito é natural, e por tal, inalienável perante as mãos estatais. Entretanto, no período mais contemporâneo, e principalmente, a partir de Kelsen a discussão de Ciência Jurídica e Direito fica retomada, onde então, se aborda acerca da lei escrita (positivada) para legitimar qualquer ação, omissão ou propriedade de direito sobre qualquer sujeito. No momento histórico em debate acerca do fundamento da lei e da Ciência Jurídica enquanto parte do conhecimento a estudar os direitos, fora possível ver por um lado a Escola Livre do Direito, que na verdade buscava uma associação à sociologia e ciência política, por outro o positivismo, que impunha a objetividade como plano central as interlocuções jurídicas.

${ }^{4} \mathrm{O}$ plano da eficácia será definido pela entrada e funcionamento efetivo da norma. Assim, o fato exposto, legislado e aprovado, somente será fato jurídico, quando concretamente se tornar eficaz. Não bastando ser somente existente e válido, para isso ver Mello (2003, p. 167)

${ }^{5}$ Influência estrutural e epistemológica principal, cuja Kelsen alimenta em sua Teoria Pura, buscando em Kant os artefatos de construção para o conhecer da norma. A ideia de préconhecimento sobre uma "coisa", que Kant aborda acerca dos elementos/conhecimentos a priori do entendimento. Utilizado por Kelsen na compreensão, por exemplo, acerca da lei e regra, onde essas estão em pleno conhecer público, e para tal, ninguém poderá justificar algo pelo não conhecimento da lei. 
${ }^{6} \mathrm{Ou}$ seja, os aforismas como: o conhecimento da lei em sentido particular da ação volitiva; a ideia de a "letra da lei" ser o principal, e jamais, buscar em outra ciência ou conhecimento a legitimação para aplicação diferenciada da lei; a lei se faz simplesmente por ser lei, ou melhor, não necessita de nenhum pressuposto moral para se construir e ser aplicada.

${ }^{7}$ Tanto foi sua consolidação enquanto Estado, Governo e Lei, que na análise dos depoimentos de Hermann Goering (GOLDENSOHN, 2004, p. 142-177) é possível perceber de que forma a banalidade e a proximidade entre os atos formalmente executados, não eram pensados, ou mesmo interpretados para tal fim. Forma-se uma tecnicidade quanto a atos executados, sem mesmo ter a perspectiva de imaginar, pensar ou discriminar, suas consequências - humanas e materiais.

${ }^{8}$ Nisto, a contribuição de Luc Ferry (2010, p. 175-179) é diferencial, pois na análise de estudo do debate entre racionalistas, empiristas e céticos, a existência ou não de Deus estabelece como tema central a razão. Conferindo a discricionariedade de Kant, a resposta do século, ou seja, a falta de capacidade para conhecer.

${ }^{9}$ Nisto, observa-se que a diferença entre a legitimidade moral kantiana segue a perspectiva de sujeito racional e autônomo, enquanto para o pensamento normativo, os sujeitos estão compilados como "coisas" ou "animais" que não são capazes de não agir ou agir em dada circunstância. Não é percebido o homem como capaz e racional, mas como ser que obedece às regras, e mero intérprete das ações da realidade.

${ }^{10}$ Assim, distancia-se bastante das éticas utilitaristas e pragmáticas, daquela cuja ação depende de uma consequência, seja na maximização da felicidade/prazer ou da praticidade do que venha a ser labutado.

${ }^{11}$ Para Morente (1980, p. 255-257) a natureza do imperativo está relacionada principalmente pela condição lógica que o sistema kantiano desenvolve. Sendo de entendimento primeiro, a consideração da razão pura, para somente depois, observar a razão prática e as elucubrações dos juízos. O imperativo é a reunião dos elementos necessários para se viver moralmente.

${ }^{12}$ De acordo com Kant (1995, p. 237) a dedução de criar juízos perante um pensamento dogmático terá como fator determinante, não somente a adaptação a condição empírica, mas também a pressuposição de haver reflexão e crítica perante dado julgamento. 